\title{
PRESERVAÇÃO DO PATRIMÔNIO ARTÍSTICO: MAPEAMENTO DOS BENS MÓVEIS TOMBADOS PERTENCENTES AO PERÍODO DO BARROCO BRASILEIRO
}

\author{
Maria José de Azevedo Marcondes \\ Viviane Bosso Pancheri \\ IA-UNICAMP \\ CNPq - Conselho Nacional de Desenvolvimento Científico e Tecnológico
}

Este texto é resultado de uma pesquisa de Iniciação Científica, desenvolvida no Instituto de Artes da Universidade Estadual de Campinas, que teve como objetivo estudar e ampliar o conhecimento na área de mapeamento do patrimônio nacional móvel, identificando seus atuais locais de permanência, seus originais locais de produção hegemônica, sua documentação e importância; elaborando uma breve análise das condições sobre o estado físico que se encontram, como foi e quais são os artistas envolvidos com estas produções.

Para o desenvolvimento desta pesquisa foi feito um recorte no tempo focalizando o século XVIII, referente à produção artística barroca. Destaca-se, no entanto, que os objetivos foram relacionados com as questões voltadas à documentação desta produção e com as condições de conservação. Para o desenvolvimento deste trabalho foram pesquisadas diversas fontes secundárias, processos de tombamento nos arquivos e na Biblioteca Noronha Santos do Instituto do Patrimônio Histórico e Artístico Nacional - IPHAN- e visitas técnicas nos museus da cidade de São Paulo: Museu de Arte de São Paulo, Pinacoteca do Estado e Museu de Arte Sacra. E, na cidade do Rio de Janeiro o Museu de Belas Artes.

O texto apresenta de forma sucinta a trajetória das políticas de preservação do citado organismo nacional de preservação e a caracterização dos bens móveis. A seguir, são feitas algumas referências ao período barroco para situar o mapeamento dos bens móveis e uma análise das condições necessárias para a conservação desses bens.

Maria Cecília Londres Fonseca e José Reginaldo Santos Gonçalves descrevem que um dos precursores dos estudos sobre o patrimônio nacional foi Mário de Andrade, um escritor modernista, um personagem culto de sua época que se dedicou ao tema que acabou fazendo parte da política voltada ao Patrimônio Nacional.

Mário elaborou o projeto inicial que serviu, e serve até hoje, de base para exaltar a importância da preservação do que restou do passado. 
Tinha como objetivo incentivar estudos detalhados sobre monumentos e responsabilizar o Estado pela fiscalização da condição em que eles se encontravam. Também ressaltava a importância de incluir nessas equipes de estudos especialistas de várias outras áreas e não somente profissionais de arquitetura como era até aquele instante. $\mathrm{O}$ estudo deveria ser minucioso, contendo o máximo de dados possíveis sobre um monumento (altura, peso, químicas, tintas, proporções etc.) e deveria também ser registrado com fotografias, que para aquele momento era uma tecnologia considerável.

Mario de Andrade propunha que a responsabilidade sobre o patrimônio deixasse de ser unicamente função do Museu Histórico, pois este não tinha condições estruturais e financeiras de arcar com as memórias e as ruínas de um país do tamanho do Brasil. Por isso o projeto sugeria que cada estado, incluindo o Distrito Federal, fosse responsável pelos estudos de seu território, pelos registros, pela documentação, pela conservação e especialmente pelos tombamentos. Outro tópico importante de seu projeto era a inclusão do povo, fazendo também a função de "dono", neste processo inteiro. O povo era como a resultante dos acontecimentos históricos e era aquele que absorvia as realidades por ela oferecidas; assim ajudava a criar a identidade brasileira.

O projeto implantado foi o de Rodrigo Mello Franco de Andrade, que incorporou algumas idéias iniciais de Mário de Andrade. Rodrigo estimulava e elaborava discussões sobre critérios culturais e valores para que fosse possível criar representações que reforçariam o caráter nacional envolvido em todo trabalho que estava sendo efetuado. Propunha a elaboração de narrativas em torno do patrimônio nacional com base em dados, documentos e fotografias, tornando o SPHAN uma espécie de grande base de registro da trajetória da cultura brasileira através do conhecimento, do contato com os elementos da tradição, fazendo a ponte entre presente e passado.

De 1937 até o fim da década de 60, Rodrigo Melo Franco de Andrade esteve diante da diretoria do SPHAN. Período caracterizado como "fase heróica" do SPHAN, ou fase de atuação mais significante. Tinha como causa o sentimento nacionalista, o processo de evolução/progresso do povo brasileiro como civilização e a proteção desta através dos monumentos preservados, da tradição. Acreditava também que para que o povo pudesse se sentir parte dessa história ou se apropriar dela, ele precisaria estar em constante convívio com os monumentos, como já alertava o escritor Mário de Andrade. 
Verificou-se que os tombamentos realizados para a preservação dos bens móveis foram inferiores aos demais tombamentos, pois na chamada "fase heróica" do SPHAN, fase na qual foi concluído o maior número de tombamentos, os bens móveis representavam $0,3 \%$ dos bens tombados, sendo que a produção hegemônica foi no estado de Minas Gerais, Bahia, Rio de Janeiro e São Paulo (contando os bens produzidos em outras regiões e sediados em coleções em São Paulo).

Estes bens móveis são representados em sua maioria por objetos religiosos, ornamentos e imagens, pois grande parte desses tombamentos faz referência às capelas, igrejas, mosteiros e conventos.

Conforme citou Rodrigo Mello Franco de Andrade: "Em relação aos bens móveis de interesse histórico, o Serviço não pôde ainda iniciar sequer o seu tombamento sistemático. Tal é a sua profusão, tal a variedade de sua natureza, - obras de arte pura, obras de arte aplicada, obras de valor histórico, obras de interesse etnográfico, arqueológico ou bibliográfico -, que serão necessários muitos anos de esforço esclarecido e paciente para inventariar as coisas desse gênero cuja preservação se imponha o interesse da nossa coletividade. Por isso mesmo o SPHAN se tem limitado, a esse respeito, a empenhar-se no sentido de proceder ao inventário dos museus e coleções públicas e particulares, a que esses bens tenham sido incorporados".

Outra verificação do trabalho refere-se ao fato que o Livro do Tombo que mais apresenta bens móveis tombados é o Livro das Belas Artes. Logo em seguida, respectivamente, os Livros do Tombo Histórico, o Livro do Tombo Arqueológico e, o Livro do Tombo das Artes Aplicadas.

Conforme exposto acima Minas Gerais (Ouro Preto, Sabará e Mariana), Bahia e Rio de Janeiro são hoje os três estados com mais tombamentos de bens móveis e integrados do século XVIII. Praticamente todos estes bens são obras e objetos barrocos.

Os bens móveis barrocos tombados isoladamente (que não são bens integrados) em Minas Gerais são: a coleção de ex-votos do Santuário de bom Jesus de Matosinhos (Congonhas), as obras de talha do Santuário do Bom Jesus de Matozinhos (Conceição do Mato Dentro), a imagem de São Francisco de Paula feita por Aleijadinho (Abre Campo), o lavatório da Igreja de Nossa Senhora da Boa Viagem (Belo Horizonte), as obras de talha dos retábulos e púlpitos na capela da fazenda da Jaguara feitas por Aleijadinho (Nova Lima) e a imagem de Santana também feita por Aleijadinho (Ouro Preto). 
A Maioria dos bens móveis compõe os chamados bens integrados estando presentes em igrejas, conventos, mosteiros, oratórios, hospícios, engenhos, casas, museus e coleções. As igrejas, conventos, capelas e mosteiros se destacam por possuir a grande quantidade dos bens barrocos; muitas delas acabaram sendo transformadas em museus de arte sacra, como é o caso do Mosteiro da Luz, atual Museu de Arte Sacra de São Paulo. Nem sempre estes locais são adequados para se manter as obras e os objetos, pois eles ficam expostos o tempo todo aos agentes degradantes e ao público, que muitas vezes não é preparado para interagir em espaços assim.

$\mathrm{Na}$ Bahia os destaques foram os artistas José Joaquim da Rocha, Veríssimo de Souza Freitas, José Teófilo de Jesus e Frei Agostinho da Piedade. No Rio de Janeiro, as primeiras grandes pinturas do século XVIII eram influenciadas diretamente pelo barroco ilusionista português, com pontos de fuga, sem molduras e representando na maioria das vezes cenas celestiais, como anjos e aparições. A técnica italiana também chegou a fazer parte das pinturas no Rio. As obras do Rio de Janeiro possuem um elemento que dificulta bastante os estudos e os inventários: a falta de datas e assinaturas. Em virtude disso, quase não conhecemos os artistas daquele período, salvo algumas exceções como o grande Mestre Valentim e frei Ricardo do Pilar.

Em Minas Gerais o número de pessoas envolvidas com os bens do século XVIII é exorbitante. Através dos arquivos do IPHAN, encontram-se dezenas de nomes como: Antônio Francisco Lisboa (o Aleijadinho), Bernardo Pires da Silva, D. Vicente José de Nicolta, Felipe Vieira, Francisco Vieira Servas, Francisco Xavier de Brito, Jerônimo Feliz Teixeira, João Antunes de Carvalho, João Carvalhais, João Nepomuceno Correia e Castro, José Coelho de Noronha, José Gervásio de Sousa, José Rodrigues da Silva, José Soares de Araújo, Manoel Ferreira de Matos, Manuel da Costa Athaíde, Manuel Antônio da Fonseca, Manuel Francisco Lisboa (pai de Aleijadinho), Manuel Gomes da Rocha, Manuel Ribeiro Rosa, Manuel Rodrigues Coelho, Manoel Victor de Jesus, Romão dias Pereira Cardoso, Salvador de Oliveira, Silvestre de Almeida Lopes e Tomás de Maia Brito, entre muitos e muitos outros.

São centenas de locais, distribuídos entre os estados brasileiros, que foram identificados e abrigam todas estas obras. Por exemplo, em: Alagoas, Bahia, Ceará, Espírito Santo, Goiás, Maranhão, Minas Gerais, Mato Grosso, Pará, Paraná, Pernambuco, Rio de Janeiro, Rondônia, Sergipe e São Paulo. 
Além dos tombamentos foi utilizado para a proteção dos bens: os inventários de identificação (nomenclatura usada pela UNESCO). Eles são trabalhos cuidadosos de pesquisa que têm como objetivo identificar e encontrar razões para preservar um determinado bem. Essas razões são como pistas dadas pelo objeto estudado. Elas buscam as mais diversas linguagens que indicam traços da história e da confecção de cada objeto. Através dos inventários é possível saber se um objeto deve ser preservado ou não.

Outra atitude também foi tomada para tentar proteger o patrimônio móvel: a criação de Museus. O SPHAN criou um molde para várias instituições, originando vários museus como: o Museu Nacional, o Museu Histórico, o Museu da Inconfidência - MG, o Museu das Missões RS, o Museu de Arte Sacra - BA, etc.

Muitos e muitos museus foram criados, mas poucos mantiveram boas condições de funcionamento. Os museus que conseguiram se destacar com qualidade foram: o Museu do Ouro, Museu das Missões e o Museu da Inconfidência.

A conservação dos bens não deve ser uma ação destinada à recuperação, mas destinada á prevenção de futuros danos. Para isso ela deve ser construída sobre as bases do constante estudo e do controle dos elementos que favorecem a degradação. Por isso, é mais que necessário a colaboração de grandes profissionais de diversas áreas, como: artistas, arquitetos, físicos, químicos, historiadores, engenheiros, etc.

Todos esses profissionais envolvidos são responsáveis pela formulação de exames científicos que identificam os materiais empregados na elaboração dos bens móveis e suas principais características. Todos os estudos e investigações devem ser cuidadosamente registrados.

As medidas de preservação devem ser sempre correspondidas com o elemento específico de degradação que envolve o bem. Em muitos casos, isso só é notado quando a degradação já atingiu um estado avançado.

Isolar um bem móvel porque está em processo de degradação não resolve nenhum problema. O fator mais importante, para que os bens móveis sejam realmente preservados, é a qualidade de seu ambiente de permanência. Neste ambiente devem ser notados: a umidade relativa do ar, a iluminação, a poluição, os agentes biodeterioradores e a ação do próprio ser humano.

Um dos maiores motivos de destruição de bens móveis orgânicos (papéis, madeiras, tecidos...) é a umidade relativa do ar. Estes materiais absorvem e perdem as moléculas de água com grande facilidade. A grande 
concentração de umidade favorece a proliferação de fungos e consequentemente a existência de substâncias ácidas produzidas por eles. Quando o caso é o inverso e a unidade do ar é baixa, as estruturas de flexibilidade de muitos materiais são comprometidas. Associado à umidade, o calor favorece reações e ciclos de reproduções de várias espécies de insetos.

A umidade do ar em ambientes que abrigam os bens móveis deve ser constantemente observada e controlada. Em muitos casos, aparelhos como condicionadores de ar, ventiladores, umificadores e desumificadores auxiliam este cuidado.

A luz, que é outro fator de degradação, tem seus efeitos facilmente notados. Ela causa perda de cor, amarelamento de certos vernizes e tem ligação direta com a dilatação de alguns metais. Ela também é a condutora de irradiações imperceptíveis aos olhares humanos, como os raios ultravioleta e infravermelho, mas que são aparentemente notados com o tempo devido ao seu efeito acumulativo. Por isso que são proibidos os flashes nos museus, e recomendado que as obras não fiquem vinte e quatro horas sob a iluminação, seja artificial ou natural. Isso pode ser controlado com auxílio de janelas, cortinas, persianas e filtros protetores. Os bens móveis devem ter períodos de descanso em ambiente escuro.

$\mathrm{O}$ ar como grande via de agentes destruidores, não traz somente a umidade para os objetos, mas traz também partículas de poluição provenientes de gases industriais, gases de decomposições, cloretos, fuligens e poeira. Essas partículas estão em suspensão em todo lugar constantemente. Em alguns casos, as partículas mais sólidas proporcionam efeitos abrasivos e acabam corroendo, manchando, craquelando e escurecendo determinados objetos.

Além dos elementos presentes no ar, os acervos de bens móveis precisam ser protegidos de insetos, animais e fungos. Os insetos se alimentam e se reproduzem entre os bens. Geralmente são cupins ou térmitas, brocas, traças, piolhos -de -livros e baratas. Procuram nos bens móveis: celulose, amidos e açúcares.

A higienização mal feita dos locais e o controle inadequado da climatização do ambiente podem favorecer o aumento das populações desses insetos. O controle dessas populações é muito difícil, pois substâncias que os exterminam podem afetar os próprios bens.

Os fungos degradam geralmente os objetos orgânicos, como papéis e madeiras. Só aparecem quando a umidade, o substrato, a luz, o 
oxigênio e a temperatura favorecem seu desenvolvimento. Estes organismos eliminam substâncias que também mancham os objetos.

A preocupação em manter a integridade de todos os materiais tombados é vinculada com a preocupação de manter a integridade da saúde das pessoas que convivem com eles, como os funcionários, os restauradores e os visitantes. Por isso, toda substância ou processo de preservação deve ser controlado e inspecionado constantemente por especialistas.

De todos esses problemas que enfrentados para conservar o patrimônio móvel nacional, nenhum deles é tão perigoso e tão degradante quanto a ação do próprio homem. Restaurações inadequadas e falta de preparo para o manuseio correto dos objetos danificam muitas obras. Roubos e vandalismos destroem e eliminam do convívio social traços importantes de nossa história, de nossa identidade. O desrespeito com regras dos museus e dos limites para a apreciação desses bens móveis também incorporam a lista dos perigos os quais eles estão subordinados.

O grande desafio não é somente restaurar, conservar ou preservar os bens móveis. O desafio para garantir vida longa ao patrimônio se faz da dificuldade de manter a qualidade destes juntamente com a conscientização do povo brasileiro.

Em síntese concluímos que a pesquisa colaborou para a compreensão dos processos necessários para a agregação dos bens culturais em âmbito nacional, especificamente dos bens móveis, e colaborou para a análise destes bens através da história e da política de preservação do Brasil.

Foi possível compreender os procedimentos de análises dos bens e/ou de objetos, para ser determinado como parte do patrimônio histórico e artístico nacional. Além de conhecer as discussões sobre os valores artísticos, históricos e documentais envolvidos na trajetória da efetuação de um tombamento. Através dos estudos e dos dados disponíveis pelo IPHAN, conseguiu-se identificar: a produção hegemônica do período do barroco, os locais dessa produção e quais elementos dessa produção foram adicionados ao patrimônio nacional, representando, hoje, parte significativa do conjunto todo tombado. Tão importante quanto conhecer o longo caminho percorrido dos bens até o ato do tombamento, foi poder compreender a condição dos bens móveis no Brasil, como a necessidade de medidas de segurança mais severas. 